\title{
Effects of Temperature on Morphological, Structural and Optical Characteristics of CdTe Films for PV Applications
}

\author{
${ }^{* 1}$ M. A Salawu, ${ }^{2}$ A. B Alabi, ${ }^{3}$ J. T. Adeleke, ${ }^{4 H}$. T.Sulu, ${ }^{5}$ S. B. Sharafa and ${ }^{2 T}$. Akomolafe \\ ${ }^{1}$ Physics/Electronics Unit, Kwara State Polytechnic, llorin \\ 2Department of Physics, University of Ilorin, llorin, Nigeria \\ ${ }^{3}$ Department of Physics, Osun State University, Oshogbo, Nigeria \\ ${ }^{4}$ Physics/Electronics Unit, Umaru Ali Shinkafi Polytechnic, Sokoto, Nigeria. \\ ${ }^{5}$ Department of Physics, Usmanu Danfodiyo University Sokoto, Sokoto, Nigeria \\ [ ${ }^{*}$ Corresponding Author: E-mail: abideen2004@gmail.com; E: 08030788553]
}

\section{ABSTRACT}

Cadmium telluride (CdTe) is a direct band gap semiconductor for direct light-to-electricity conversion. The films are promising photovoltaic materials for $\mathrm{CdS} / \mathrm{CdTe}$ solar cells because of its energy band gap of $1.5 \mathrm{eV}$ and higher absorption co-efficient $\left(>10^{4} \mathrm{~cm}^{-1}\right)$. This work presents the characterization of $1 \mu \mathrm{m} \mathrm{CdTe}$ films for photovoltaic applications. The films were deposited on cleaned glass substrates using thermal evaporation. The effect of annealing temperatures (as deposited, $400^{\circ} \mathrm{C}$ and $500^{\circ} \mathrm{C}$ ) on morphological, structural and optical characteristics of CdTe films was investigated for an hour and characterized with Scanning Electron Microscope (SEM), Powder X-ray diffraction (PXRD) and UV-Visible spectrophotometer. The results revealed that the reflectance characteristics of CdTe films depend on the wavelength of electromagnetic spectra. The maximum percentage optical transmittance of $\mathrm{CdTe}$ films for as-grown, $400^{\circ} \mathrm{C}$ and $500{ }^{\circ} \mathrm{C}$ films were $59 \%, 60 \%$ and $58 \%$ respectively at $800 \mathrm{~nm}$ wavelength. The absorbance decreases with increasing in wavelength and was found to be $1.65,1.25$ and $0.85 \%$ for the as-grown, $400^{\circ} \mathrm{C}$ and $500^{\circ} \mathrm{C}$ films respectively. The absorption coefficient exhibits higher values in the shorter wavelength and decreases as the wavelength and temperatures increases and the band gap becomes wider. The SEM analyses showed that the films were homogenous and free from crystal defects. The results revealed that 1 $\mu \mathrm{m}$ CdTe film may be used as absorber layer in CdS/CdTe thin film solar cells.

Keywords: CdTe, Glass substrate, Thermal evaporation, Annealing temperature, Energy band gap

\section{INTRODUCTION}

Thin films of II-VI semiconductors are at present used in many semiconductor devices such as photo-electrochemical cells, field effect transistors, detectors, photodiodes, photoconductors and photovoltaic solar cells (Mousumi et al., 2014; Lalitha et al., 2007; Habibe and Cigdem, 1998; Khan et al., 2015).

Today, CdTe is one of the foremost thin film photovoltaic materials due to the optimum band gap of $1.5 \mathrm{eV}$ for the efficient photo conversion, high optical absorption coefficient and successful development of high efficiency solar cells and modules (Mohammed, 2013; Khan et al., 2015; Xavier et al., 2004; Patel et al., 2012).

CdTe thin film have been prepared by different techniques such as magnetron sputtering, thermal evaporation, Chemical Bath Deposition
(CBD), hot-wall vacuum evaporation etc. From the methods used for the preparation of $\mathrm{CdTe}$ films, thermal evaporation in vacuum is often preferred because of the growth under a thermal equilibrium condition and it offers great possibilities to modify the deposition conditions to obtain films with determined structure and properties (Hussain et al., 2015; Rusu, 2001).

In this present work, effects of annealing temperatures on optical, structural and morphological characteristics of thermally evaporated $1 \mu \mathrm{m}$ CdTe films were investigated. 1 $\mu \mathrm{m}$ CdTe films annealed at different temperatures have been prepared in this work. Photometric measurements (transmittance, reflectance and absorbance) of CdTe films were carried out to characterize the material in the visible region of the solar spectrum for solar cells 
applications. Powder X-ray diffraction pattern of the annealed CdTe films was also investigated and several structural parameters were calculated from the PXRD analysis. This was done to optimize the growth condition for a good quality film which will be suitable for optoelectronic devices.

\section{MATERIALS AND METHOD}

\section{Materials}

The materials used were Cadmium Telluride (CdTe) granules obtained from China Rare Metals (CRM) China (99.99 \% pure), acetone, methanol, detergent, de-ionized water and microscopic glass substrates.

\section{Method}

The glass substrates were cleaned with detergent, acetone and methanol, and then washed in an ultrasonic bath with de-ionized water. CdTe granules evaporated from molybdenum boat and deposited on to clean glass substrates as thin films form. The glass substrates were dried in a dust free atmosphere. CdTe films of thickness $1 \mu \mathrm{m}$ were deposited by thermal evaporation technique in a residual pressure of $10^{-5}$ torr. The substrates temperature was kept constant at room temperature. Thermal evaporation employs an electric resistance heater to melt the material and raise its vapor pressure to a functional range. This is prepared in a high vacuum, both to allow the vapor to reach the substrate without reacting with or scattering against other gas-phase atoms in the chamber, and reduce the inclusion of impurities from the residual gas in the vacuum chamber. The vacuum is required to allow the molecules to evaporate freely in the chamber, and they subsequently condense on all surface of substrate. The fabricated thin films were annealed at 400 and $500{ }^{\circ} \mathrm{C}$. The as-grown and annealed CdTe films were characterized with PXRD, UV-VIS spectrophotometer and Scanning Electron Microscope (SEM).

\section{RESULTS AND DISCUSSION}

The percentage reflectance characteristics of CdTe films are visualized in Figure 1 as a function of wavelength.

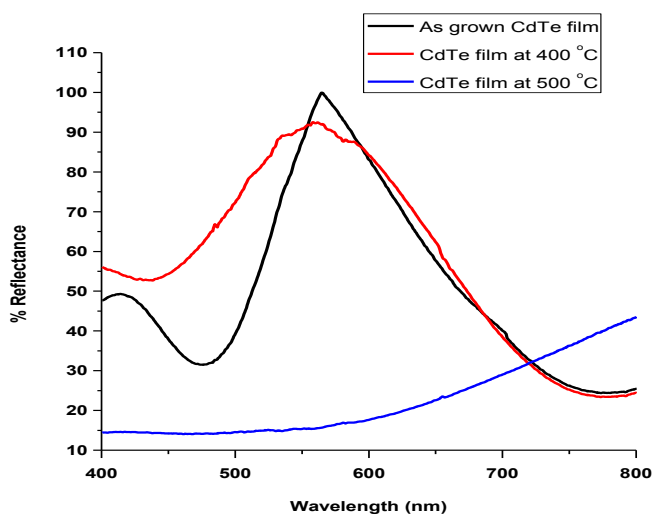

Figure 1: Reflectance of $1 \mu \mathrm{m}$ CdTe Films Annealed at Different Temperatures

It was found that the magnitude of reflectance of CdTe films vary periodically with wavelengths. Multiple oscillations occur on the reflectance curves due to interferences among multiple reflected waves. As the wavelength increases, oscillation period of these films changes. Thus, the reflectance characteristics of CdTe films are strongly dependent on the wavelength of electromagnetic spectra. Highest peak value of percentage reflectance of $99 \%$ occurred at 566 $\mathrm{nm}$ wavelengths for the as-grown CdTe film. Maximum reflectance peak of $92 \%$ occurred at $562 \mathrm{~nm}$ wavelength for 400 degree Celsius annealed film while the maximum reflectance peak of $43 \%$ was observed for annealed CdTe film at $500{ }^{\circ} \mathrm{C}$ at $800 \mathrm{~nm}$ wavelength. The reflectance spectra shows interference pattern with distinct peaks and valleys (Mousumi et al., 2014; Hussain et al., 2004).

The percentage transmittance characteristics of CdTe films are visualized in Figure 2 as a function of wavelength. 


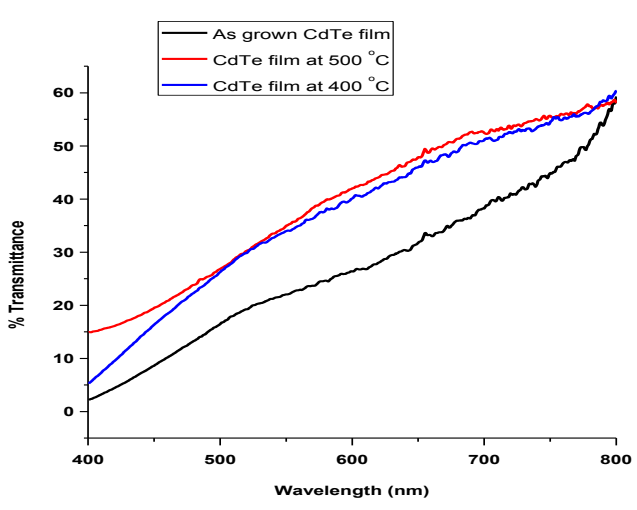

Figure 2: Percentage transmittance spectra of $1 \mu \mathrm{m}$ CdTe films annealed at different temperatures

The percentage optical transmittance spectra of the CdTe films in the wavelength range 400 to $800 \mathrm{~nm}$ are depicted in Figure 2. The percentage optical transmittance of CdTe films increases from very low value to maximum value as the wavelength increases in the visible to near infrared region of the solar spectrum. The maximum percentage optical transmittance of CdTe films for as-grown, $500^{\circ} \mathrm{C}$ and $400^{\circ} \mathrm{C}$ annealed films are $59 \%, 58 \%$ and $60 \%$ respectively at $800 \mathrm{~nm}$ wavelength. The phenomena are in good agreement with the reported work of Hussain et al. (2015) and Mousumi (2014).

The absorbance characteristics of CdTe films annealed at different temperatures are visualized in Figure 3 as a function of wavelength.

It was observed from the absorbance spectra that the absorbance decreased with increase in wavelength and found more than $1.6 \mathrm{au}, 1.2 \mathrm{au}$ and 0.8 au for the as-grown, $400^{\circ} \mathrm{C}$ and $500{ }^{\circ} \mathrm{C}$ annealed films respectively. It is found to be higher for the as-grown film in the visible region which may be attributed to its ordered structure as well as free carrier absorption and revealed the semiconducting nature of CdTe film.

The absorption coefficient characteristics of CdTe films annealed at different temperatures is visualized in Figure 4 as a function of wavelength.

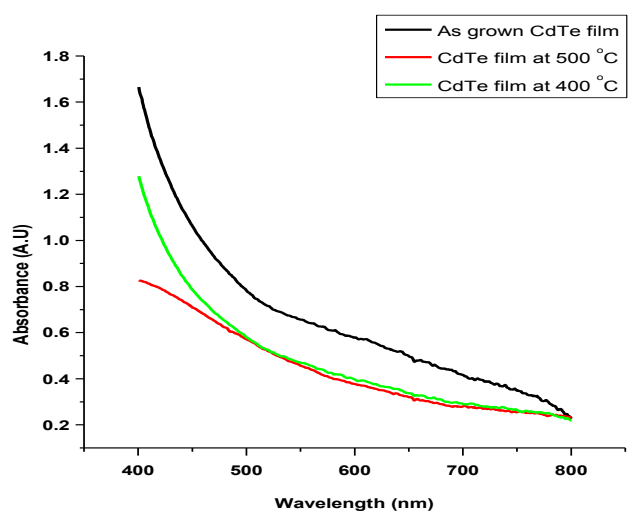

Figure 3: Absorbance spectra of $1 \mu \mathrm{m} \mathrm{CdTe}$ films annealed at different temperatures

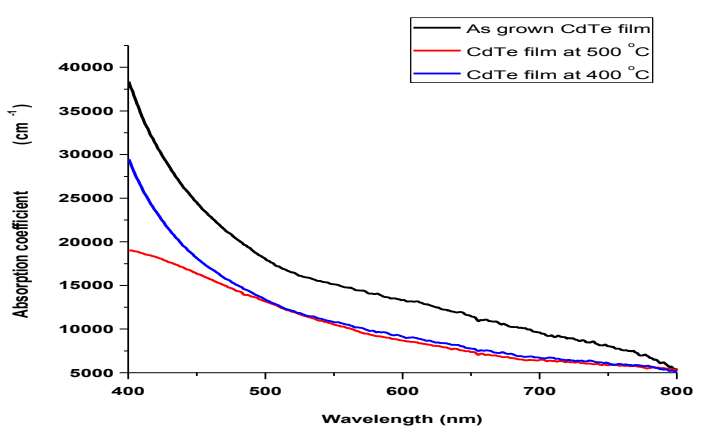

Figure 4: Absorption coefficient of $1 \mu \mathrm{m} \mathrm{CdTe}$ films annealed at different temperatures

It is observed from Figure 4 that absorption coefficient exhibits higher values in the shorter wavelength and decreases as the wavelength increases in the visible region of the solar spectrum. The value also decreases with the increases in annealing temperature. The absorption coefficients of $3.9 \times 10^{4}, 2.9 \times 10^{4}$ and $1.9 \times 10^{4}$ occurred at $400 \mathrm{~nm}$ wavelength for the as-grown, $400^{\circ} \mathrm{C}$ and $500^{\circ} \mathrm{C}$ annealed $\mathrm{CdTe}$ films. These values of absorption coefficient $\left(>10^{4} \mathrm{~cm}^{-1}\right)$ means there is large probability of the allowed direct transition (Mousumi et al., 2014). 
The variation of coefficient of extinction of CdTe films annealed at different temperatures is visualized in Figure 5 as a function of wavelength.

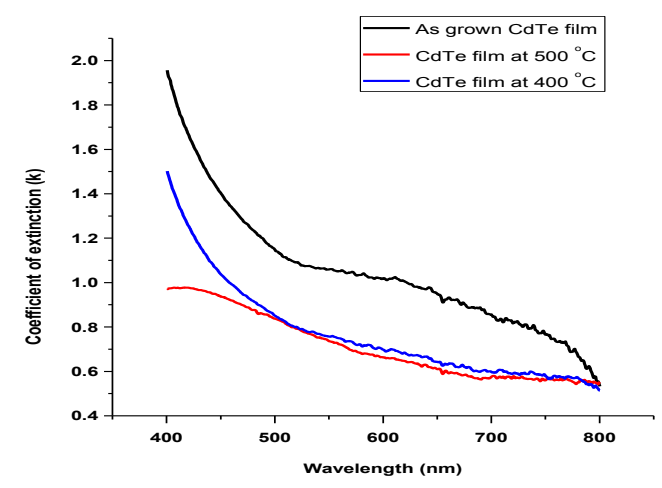

Figure 5: Variation of coefficient of extinction of 1 $\mu \mathrm{m} \quad \mathrm{CdTe}$ films annealed at different temperatures

The coefficient of extinction $(k)$ is increased with photon energy and decreases with annealing temperatures. The coefficient of extinction is found to be higher for as-grown CdTe which may be attributed to the dominance of density effect in the deposited film. The coefficients of extinction obtained were 1.92, 1.5 and 0.98 for as-grown, $400^{\circ} \mathrm{C}$ and $500^{\circ} \mathrm{C}$ annealed CdTe films.

The band gap of CdTe films annealed at different temperatures is visualized in Figure 6.

The optical band gap energies were evaluated by extrapolating the straight line of the Tauc's plot for zero absorption coefficients $(a=0)$. Approximately linear nature of the plot is observed towards the lower wavelength and exponentially behavior towards the higher wavelength which indicated the presence of direct optical transition. The exponential behavior of the plot may be attributed to the local impurities of the material. The optical energy band gap is found to be increasing as the annealing temperatures increases. The optical energy band gaps of $1.5 \mathrm{eV}, 1.6 \mathrm{eV}$ and $1.7 \mathrm{eV}$ were obtained for as-grown, $400^{\circ} \mathrm{C}$ and $500^{\circ} \mathrm{C}$ annealed CdTe films.

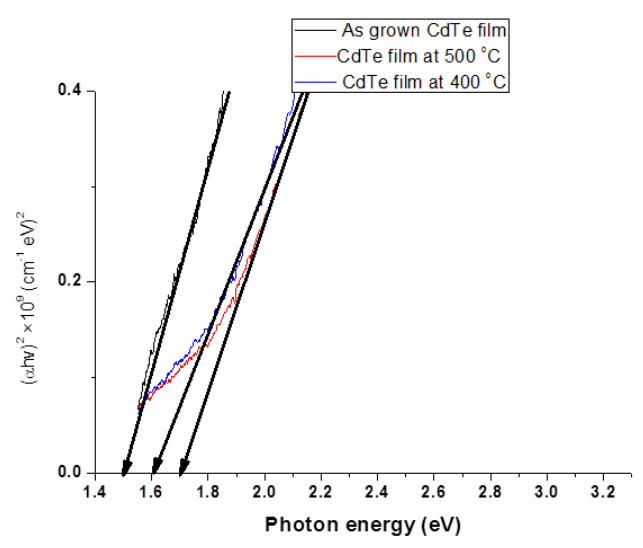

Figure 6: Band gap of $1 \mu \mathrm{m} \mathrm{CdTe}$ films annealed at different temperatures

Figure 7 to 10 showed the powder $\mathrm{x}$-ray diffraction pattern of the CdTe granules, asgrown, 400 and $500{ }^{\circ} \mathrm{C}$ annealed $1 \mu \mathrm{m}$ CdTe films.

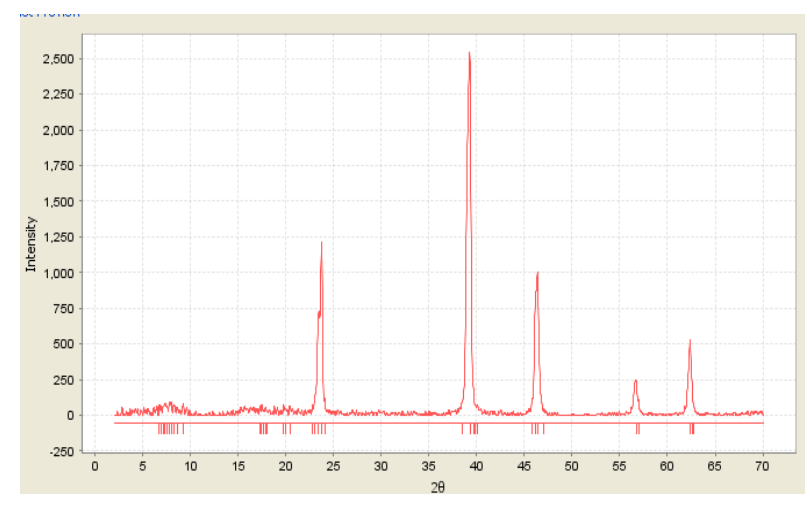

Figure 7: PXRD image of as-grown CdTe granules 


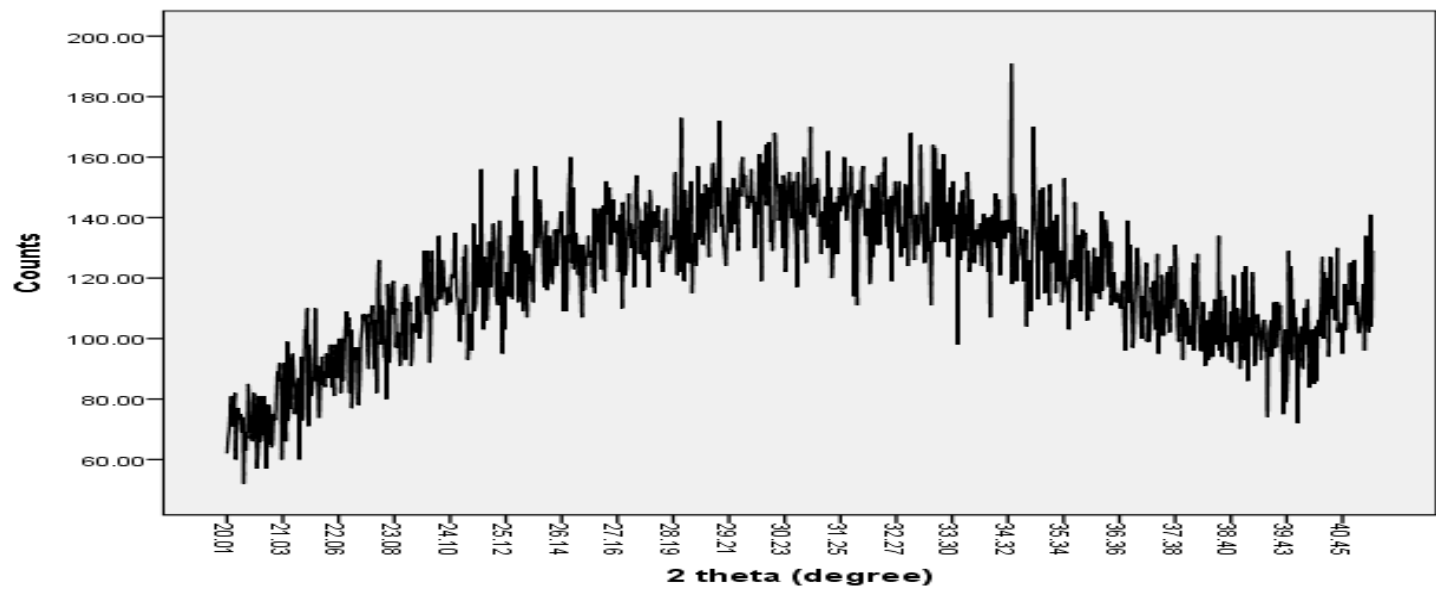

Figure 8: PXRD image of as-grown CdTe film

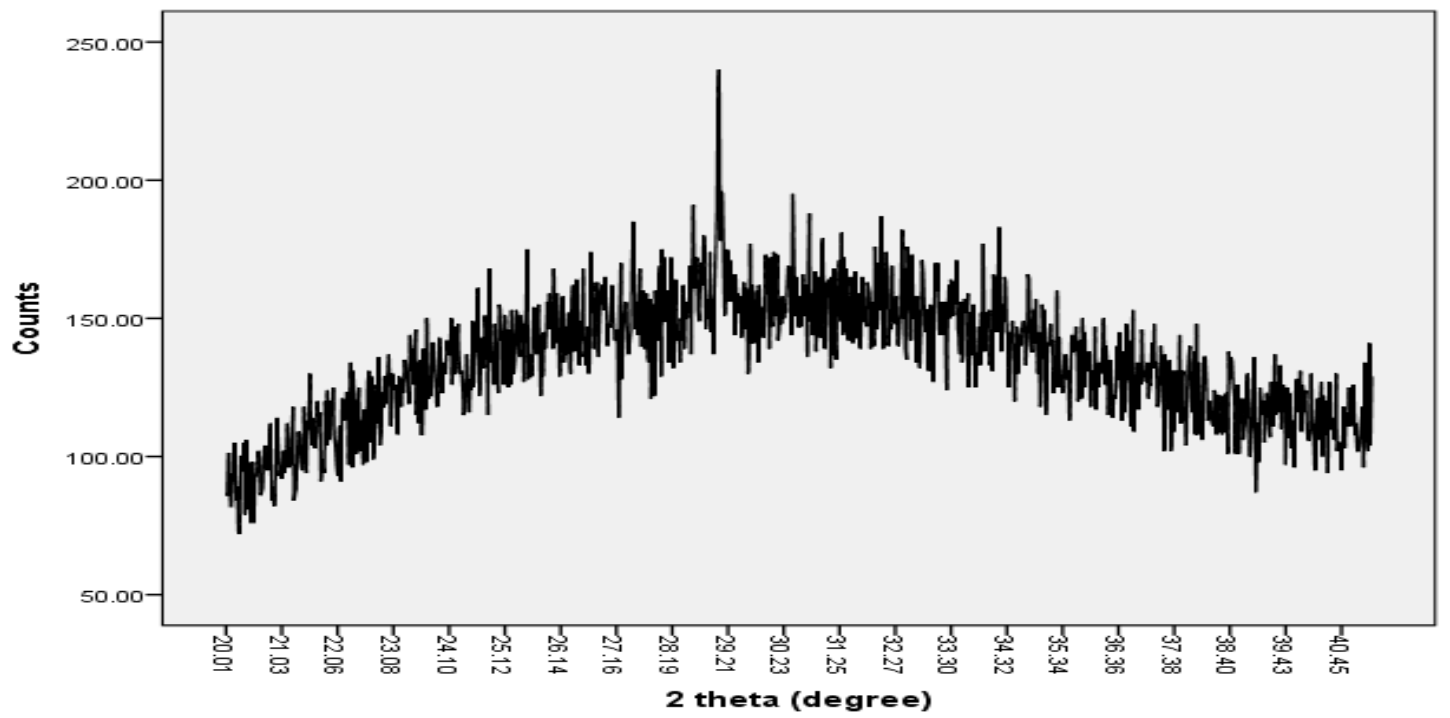

Figure 9: PXRD image of $1 \mu \mathrm{m}$ CdTe film annealed at $400^{\circ} \mathrm{C}$

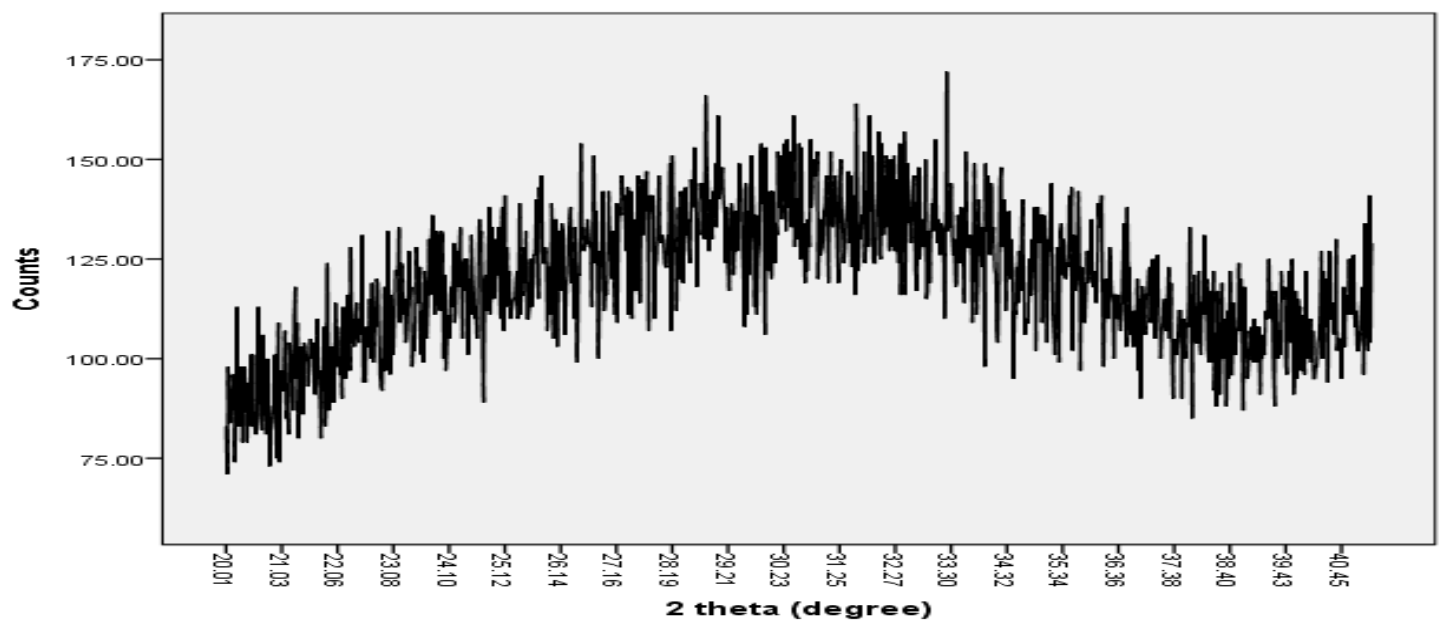

Figure 10: PXRD image of $1 \mu \mathrm{m}$ CdTe film annealed at $500^{\circ} \mathrm{C}$ 
The pulses (in arbitrary unit) and diffraction angle $(2 \theta)$ were plotted. Several peaks were observed in Figure 7 at the diffraction angles of 23, 40, 47, 57 and 62.5 degrees which confirmed the CdTe phase. The broad lump in the range of scanning angle of 20 to 40 degrees is due to the amorphous glass substrate. The diffraction peaks at position $2 \theta=24.25$ degree was observed for as-grown and $400{ }^{\circ} \mathrm{C} \mathrm{CdTe}$ films which are well indexed corresponding to prominent orientation (111) of JCPDS X-ray Powder file data 75-2086 and 15-0770 (Subhash and Dhaka, 2015).The diffraction peak (111) at approximately $2 \theta=23.8$ degree was also observed for the $500{ }^{\circ} \mathrm{C}$ annealed $1 \mu \mathrm{m} \mathrm{CdTe} \mathrm{film} \mathrm{which} \mathrm{is} \mathrm{also} \mathrm{in} \mathrm{well}$ agreement with the JCPDS data file (00-0150770) (Khan et al,. 2015).

Figure 11 (a, b, $c$ and d) showed the SEM images of CdTe granules and $1 \mu \mathrm{m} \mathrm{CdTe}$ films at different annealing temperatures.

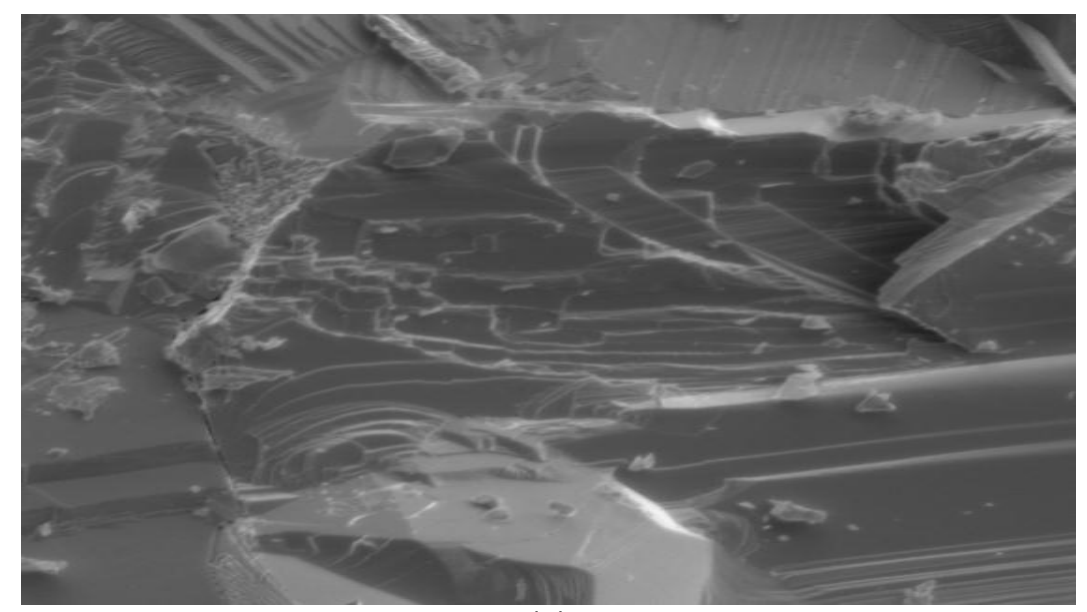

(a)

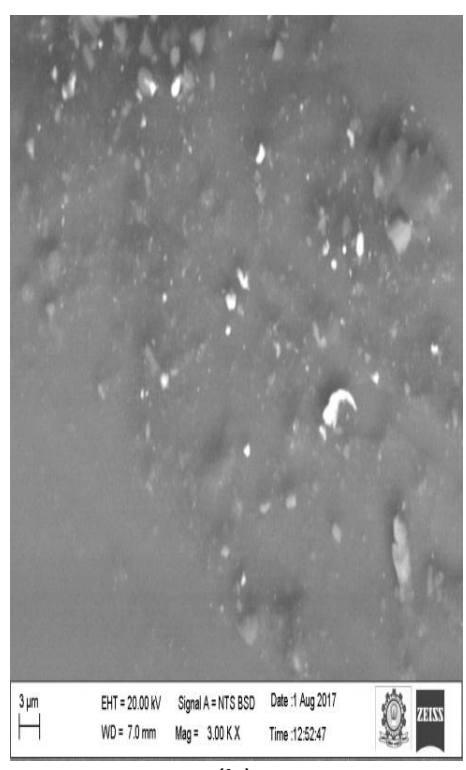

(b)

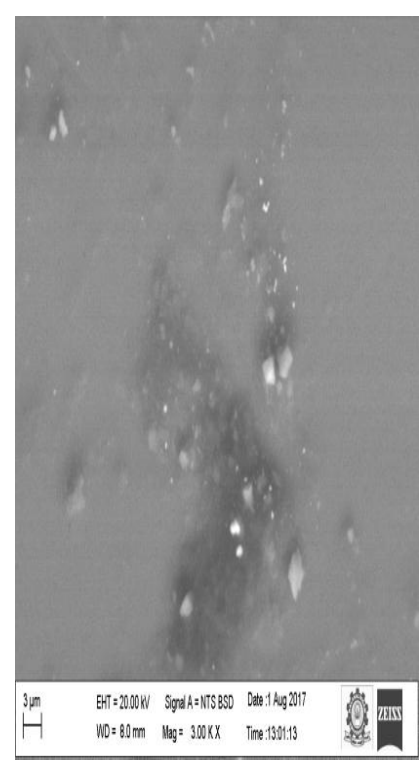

(c)

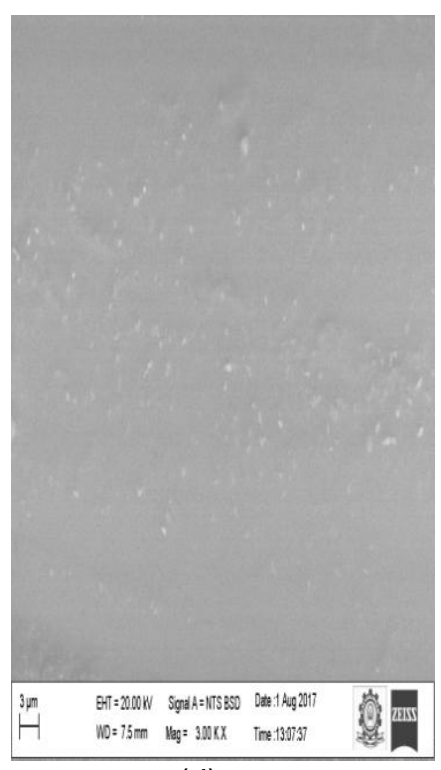

(d)

Figure 11: SEM image of (a) CdTe granules (b) as-grown $1 \mu \mathrm{m} \mathrm{CdTe} \mathrm{film} \mathrm{(c)} 1 \mu \mathrm{m}$ CdTe film annealed at $400{ }^{\circ} \mathrm{C}$ and (d) $1 \mu \mathrm{m} \mathrm{CdTe}$ film annealed at $500^{\circ} \mathrm{C}$ 
The scanning electron microscope analysis is as shown for the CdTe granules, as-grown and the annealed films at 400 and $500{ }^{\circ} \mathrm{C}$ in Figure $11(\mathrm{a}$, $b, c$ and $d$ ). The surface of the films appears clean, homogenous and pin holes free. These appearances proved the quality of the films prepared via thermal evaporation technique in high vacuum without the introduction of impurities during deposition. The annealing temperature affects the grain sizes of the films (Figure $11 \mathrm{~b}, \mathrm{c}$ and d) and also affects the band gaps of the films (Figure 6).

\section{CONCLUSION}

The effects of annealing temperatures on structural, optical and morphological characteristics of $1 \mu \mathrm{m}$ CdTe films have been presented. The reflectance spectra showed good interference phenomena with minima and maxima. The transmittance increases as the wavelength increases and the absorbance decreases with increasing wavelength. The grain sizes of the films decreases and optical energy band gaps increases as the annealing temperatures increases. The scanning electron microscope analyses give the clearer picture of each film under study. The obtained results revealed the possibility of using $1 \mu \mathrm{m}$ CdTe film as absorber layer for the development of $\mathrm{CdS} / \mathrm{CdTe}$ thin film solar cells.

\section{ACKNOWLEDGMENT}

The authors acknowledge the contributions of the Physics and Material Science Group, University of Ilorin, Department of Material Science Engineering, Kwara State University, Malete and the International Research Centre (IRC), Kalasalingam University, India towards the completion of this work.

\section{REFERENCES}

Bayham, H. and Ercelebi, C. (1998). Effects of Post Deposition Treatments on Vacuum Evaporated CdTe Thin Films and CdS/CdTe Heterojunction Devices. Turkey Journal of Physics, 22: 441-451.

Hussain, K. M. A., Mahmood, Z. H, Ishtiaque, M. S., Begum, T., Faruqe, T. and Parvin, J. (2004).
Thermal Vacuum Deposition of Cadmium Telluride Thin Films Solar Cell Material. American Journal of Materials Science and Applications, 2(6): 91-95.

Hussain, K. M. A., Mahmood, Z. H., Ishtiaque, M. Syed, Begum T., Faruqe, T. and Parvin J. (2015). Thermal Vacuum Deposition of Cadmium Telluride Thin Films Solar Cell Material. American Journal of Materials Science and Application, 2(6): 91-95.

Khan N. A., Rahman K. S., Kamaruzzaman M. I., Haque F., Islam M. A., Alam M. M., Alothman Z. A., Sopian K. and Amin N. (2015). Effect of LASER Annealing on CdTe Thin Film Deposited by Thermal Evaporation. Chalcogenide Letters, 12(4): 191- 201.

Lalitha S., Karazhanov S. Zh., Ravindran P., Senthilarasu S., Sathyamoorthy R. and Janabergenov J. (2007). Electronic Structure, Structural and Optical Properties of thermally evaporated CdTe thin films. Physica, B 387: 227-238.

Mousumi M., Shamima C., Chitra D. and Tahmina B. (2014). Substrate Temperature Dependent Optical and Structural properties of Vacuum Evaporated CdTe Thin films. European Scientific Journal, 10(3): 442-455.

Mohammed Taki (2013). Structural and Optical Properties of Cadmium Telluride Thin Film by Evaporate Technique. International Journal of Application or Innovation in Engineering and Management, 2(5): 413-417.

Patel H. S., Rathod J. R., Patel K. D. and Pathak, V. M. (2012). Structural and Surface Studies of Vacuum Evaporated Cadmium Telluride Thin Films. American Journal of Materials Science and Technology, 1: 11-21.

Rusu.C. G. (2001). On the Electrical and Optical Properties of Nanocrystalline CdTe Thin Films. Journal of Optoelectronics and Advanced Materials, 3(4): 861-866.

Subhash C. and Dhaka M. S. (2015). Preparation and Physical Characterisation of CdTe thin films deposited by Vacuum Evaporation for Photovoltaic Applications. Advanced Materials Letters. VBRI press. 1-14

Xavier Mathew, Pantoja J. Enriquez, Alessandro Romeo and Ayodhya N. Tiwari. (2004). CdTe/CdS Solar Cells on Flexible Substrates. Solar Energy. 77: 831-838. 